\title{
In Vitro Comparison of Novel Polyurethane Aortic Valves and Homografts After Seeding and Conditioning
}

\author{
Nikolaus Thierfelder, ${ }^{*}$ Fabian Koenig, ${ }^{*}+$ René Bombien, ${ }^{*}$ Cornelia Fano, $\neq$ Bruno Reichart, ${ }^{*}$ Erich Wintermantel, $†$ \\ Christoph Schmitz, * and Bassil Akra*
}

The aim of the study was to compare the behavior of seeded cells on synthetic and natural aortic valve scaffolds during a low-flow conditioning period. Polyurethane (group A) and aortic homograft valves (group B) were consecutively seeded with human fibroblasts (FB), and endothelial cells (EC) using a rotating seeding device. Each seeding procedure was followed by an exposure to low pulsatile flow in a dynamic bioreactor for 5 days. For further analysis, samples were taken before and after conditioning. Scanning electron microscopy showed confluent cell layers in both groups. Immunohistochemical analysis showed the presence of EC and FB before and after conditioning as well as the establishment of an extracellular matrix (ECM) during conditioning. A higher expression of ECM was observed on the scaffolds' inner surface. Realtime polymerase chain reaction showed higher inflammatory response during the conditioning of homografts. Endothelialization caused a decrease in inflammatory gene expression. The efficient colonization, the establishment of an ECM, and the comparable inflammatory cell reaction to the scaffolds in both groups proved the biocompatibility of the synthetic scaffold. The newly developed bioreactor permits conditioning and cell adaption to shear stress. Therefore, polyurethane valve scaffolds may offer a new option for aortic valve replacement. ASAIO Journal 2013;59:309-316.

Key Words: tissue engineering, heart valve, homograft, cell conditioning, bioreactor, synthetic scaffold

Cardiovascular diseases are currently the major cause of death. With the growing global population and the increasing life expectancy, this problem will continue to grow. The number of patients requiring heart valve surgery will increase from 290,000 in 2003 to 850,000 in $2050 .^{1}$

From the *Department of Cardiac Surgery, Laboratory for Tissue Engineering, Grosshadern Medical Center, Ludwig-Maximilian-University, Munich, Germany; IInstitute of Textile Technology and Process Engineering, Denkendorf, Germany; and IInstitute of Medical and Polymer Engineering, Technical University of Munich, Munich, Germany.

Submitted for consideration July 2012; accepted for publication in revised form January 2013.

Disclosure: The authors declare no conflicts of interest.

Reprint Requests: Dr. -Ing Bassil Akra, Department of Cardiac Surgery, Laboratory for Tissue Engineering, Grosshadern Medical Center, Ludwig-Maximilian-University of Munich; Marchioninistraße 15; 81377 Munich, Germany. Email: bassil.akra@med.uni-muenchen.de.

Copyright (C) 2013 by the American Society for Artificial Internal Organs

DOI: 10.1097/MAT.0b013e318289b95e
Currently, there are two different types of heart valve prostheses in use: mechanical and biological implants. Both types of implants offer the possibility to recover the normal valvefunction, but unfortunately with a large number of limitations. On the one hand, mechanical prostheses require life-long oral anticoagulation therapy, ${ }^{2}$ and on the other hand, the lifetime of the biological prostheses is limited. ${ }^{3}$ Therefore, it is necessary to develop a new kind of heart valve whose properties do not include the most critical disadvantages of the currently available prostheses. The development of a tissue engineered heart valve seems to be the most promising way: "Advantages of an engineered tissue heart valve would likely include nonthrombogenicity, infection resistance, and cellular viability." ${ }^{4}$

The field of tissue engineering has the aim of restoring diseased organs or lost functions by a combination of cells with scaffolds. ${ }^{5}$ Heart valve tissue engineering attempts, by an intelligent combination of these resources, to develop prostheses with a high durability and an inert surface, concerning coagulation. At the moment, three different approaches are used by research groups to achieve this aim. One possibility is the development of tissue engineered heart valves based on biodegradable scaffolds. ${ }^{6}$ The application of decellularized biological valves presents the second possibility. ${ }^{7}$ The development of a third cell-based option by using nondegradable scaffold materials is also under investigation.

The aim of the study was to compare new synthetic polyurethane (PU) scaffolds (group A) with conventional cryopreserved/thawed aortic homograft valves (group B) under analogous conditions in a newly developed bioreactor. Group $\mathrm{B}$ was used as a control group. The main interest was to study the reaction of seeded cells on variable materials to low flow shear stress after a short resting period of 24 hours.

\section{Material and Methods}

\section{Cell Isolation and Cultivation}

Saphenous vein segments, leftover from bypass operations, were used for vascular cell isolation. The study was approved by the Ethics Committee of Ludwig-Maximilian University Munich and before operation, patients gave their written informed consent for the use of their venous cells. Cells were isolated according to previously published methods. ${ }^{8}$ However, collagenase was replaced with trypsin/ ethylenediaminetetraacetic acid (EDTA) solution (10x; Sigma-Aldrich $\mathrm{GmbH}$, Taufkirchen, Germany) to preserve the remaining fibroblast (FB) cell layer. First, the vein segments 
were cannulated and rinsed with $500 \mathrm{ml}$ M199 (Biochrom AG, Berlin, Germany) supplemented with $1 \mathrm{ml}$ heparin (5000 i.E.; Ratiopharm $\mathrm{GmbH}$, Ulm, Germany) and $5 \mathrm{ml}$ gentamycin $(10 \mathrm{mg} / \mathrm{ml}$; Invitrogen AG, Darmstadt, Germany). For endothelial cell (EC) isolation, the segments were filled with trypsin/EDTA solution and incubated for 25 minutes at $37^{\circ} \mathrm{C}$. For $\mathrm{FB}$ isolation, the segments were incubated for 30 minutes at $37^{\circ} \mathrm{C}$ with $20 \mathrm{mg}$ collagenase solved in $10 \mathrm{ml}$ of human serum albumin (200 g/L; Baxter GmbH, Unterschleißheim, Germany). The obtained cells were initially cultivated in $12.5 \mathrm{~cm}^{2}$ culture flasks in EC growth medium (ECGM; Promocell $\mathrm{GmbH}$, Heidelberg, Germany) supplemented with $6 \%$ fetal calf serum (Lonza GmbH, Köln, Germany) and $0.2 \%$ penicillin/ streptomycin (Sigma-Aldrich $\mathrm{GmbH}$, Hamburg, Germany) and FB growth medium (FGM; Promocell GmbH, Heidelberg, Germany) supplemented with $11 \%$ fetal calf serum and $0.2 \%$ penicillin/streptomycin, respectively. Medium was changed every 2-3 days. Cells were passaged at confluency.

\section{Scaffolds}

Polyurethane valves (group $\mathrm{A}, \mathrm{n}=4$; Figure 1A) and homografts (group $B, n=4$; Figure 1B) were used as scaffolds for the development of a new tissue engineered heart valve.

Polyurethane scaffolds. Polyurethane scaffolds with a diameter of $24 \mathrm{~mm}$ were manufactured by a spraying technique (patent DE 2806030 C2). Randomly oriented PU fibers were measured to have a median diameter of $1.55 \mu \mathrm{m}$ (Figure 3A). The fibers formed a sheet with a thickness of $0.3 \mathrm{~mm}$. Surface modification was not realized for the cell-seeding procedure. For seeding purpose, PU scaffolds were sent to a certified sterilization supplier and were $\gamma$-sterilized at $10 \mathrm{kGy}$. For safe handling, the scaffolds were fixed to a special Teflon (Sahlberg GmbH\&Co. KG, Munich, Germany) mounting (Figure 1C) by a continuous circular suture using a surgical thread (Suprolene 3/0, Resorba GmbH, Nürnberg, Germany) prior to cell seeding. The mounting was designed for application in the seeding device and the conditioning bioreactor.

Homografts. Heart valve donors had an average age of $52.25 \pm 5.74$ years at the date of explantation. Exclusion criteria for the experiment were any signs of insufficiency or any macroscopic damage. Average storage time was $7.33 \pm 2.11$ years. Cryopreservation of the homografts was performed according to previously published methods. ${ }^{9}$ Scaffolds with a diameter of $27 \mathrm{~mm}$ were thawed in Ringer solution at $56^{\circ} \mathrm{C}$ and washed in Earle's M199 (Biochrom AG, Berlin, Germany) for 2 hours at room temperature (RT). Homografts were sutured to the Teflon mounting (Figure 1C) by single stitches using a surgical thread (Suprolene).

\section{Cell Seeding and Conditioning}

For better endothelialization results, the scaffolds were pre-seeded with $\mathrm{FB}$, followed by colonization with EC. The seeding procedure using a $3 \mathrm{D}$ rotating seeding device (Figure 2A) was performed as previously described. ${ }^{9,10}$ Briefly, $92.11 \pm 11.08 \times 10^{6} \mathrm{FB}$ (difference of counted cells in the suspension before and after seeding procedure) in $100 \mathrm{ml}$ supplemented FGM were dynamically seeded onto the native scaffolds for 24 hours (running phase: 2.5 minutes; holding phase: 30 minutes). Gas exchange was ensured by a silicone membrane. After FB seeding, the scaffolds were transferred to a glass bin containing $200 \mathrm{ml}$ fresh supplemented FGM and were cultured for 24 hours under static conditions. In the following 5 days, the valves were incubated in a novel self-made conditioning bioreactor (EU-Patent pending: EP10166094.2; Figure 2B). ${ }^{11}$ During this period, the valves were perfused with $400 \mathrm{ml}$ supplemented FGM by an increasing sinusoidal pulsatile flow for 48 hours at $750 \mathrm{ml} / \mathrm{min}(\approx 24 \mathrm{bpm})$ and 72 hours at $1100 \mathrm{ml} / \mathrm{min}(\approx 35.5 \mathrm{bpm})$. Half of the supplemented FGM was exchanged after 2 days. The conditioning period was followed by a second seeding procedure for the EC $\left(96.48 \pm 8.05 \times 10^{6}\right.$ cells). The EC seeding, the subsequent second resting period, and the final conditioning procedure were performed as described for FB; however, supplemented ECGM was used for cell nutrition. The performance of the valve leaflets was controlled and documented using an endoscope (Figure 2B5).
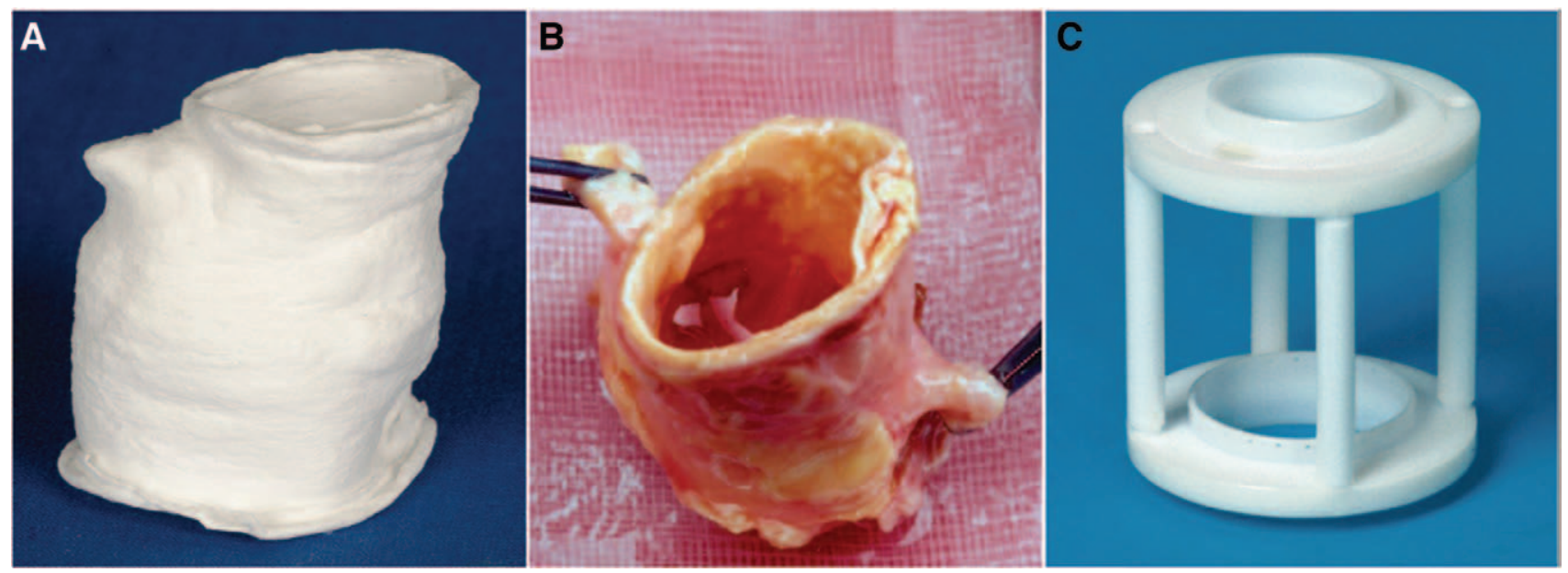

Figure 1. A: Sprayed polyurethane (PU) scaffold, diameter: $24 \mathrm{~mm}$, group $A(n=4)$. B: Cryopreserved/thawed homograft, diameter: $27 \mathrm{~mm}$, group $B(n=4)$. C: Teflon mounting for valve fixation in the seeding device and the conditioning bioreactor. Valves were fixed with a surgical thread in a continuous suture technique (polyurethane), respectively, single stitches (homograft). 

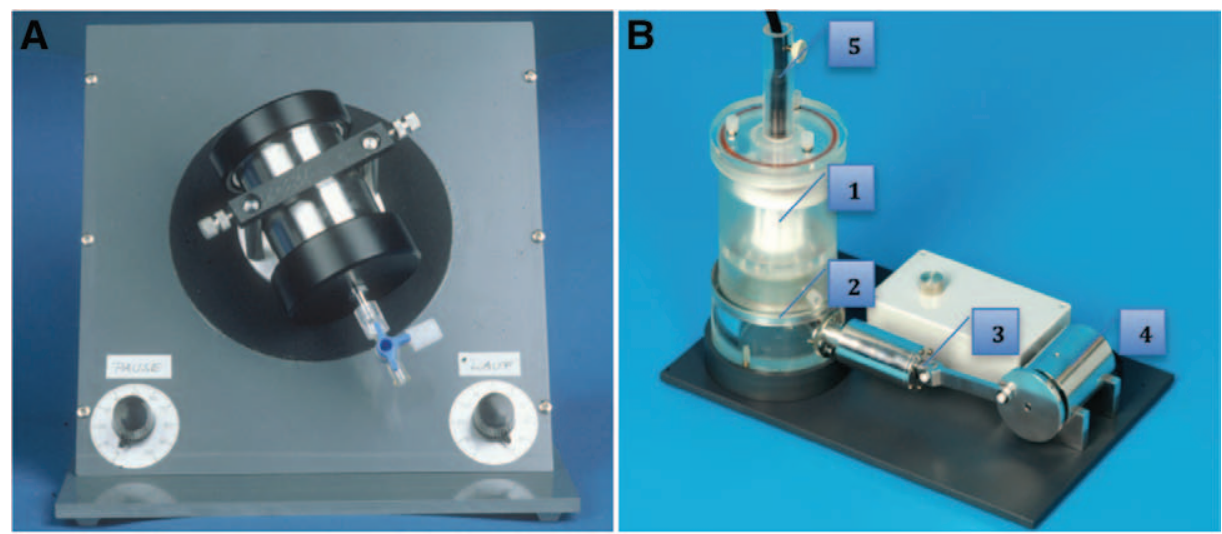

Figure 2. A: Bioreactor for 24 hours $3 \mathrm{D}$ cell seeding (running phase $=2.5 \mathrm{~min}$, holding phase $=30 \mathrm{~min}$ ).$^{10} \mathbf{B}$ : Bioreactor for 5 day conditioning period ${ }^{11}(750-1100 \mathrm{ml} / \mathrm{min})$. B1: Mounting with polyurethane scaffold placed in the incubation chamber filled with $400 \mathrm{ml}$ culture medium during the experiment. B2: Silicone membrane for conduction of pulsatile movement to the culture medium. B3: Piston for generation of pulsatile movements. B4: Electronic motor with eccentric piston rod. B5: Endoscope for the monitoring of valve performance.

\section{Evaluation Methods}

Scanning electron microscopy (SEM), immunohistochemistry $(\mathrm{IHC})$, and real-time polymerase chain reaction (PCR) were used for evaluation. Samples were taken from veins, cell cultures, and native scaffolds, before and after each processing step. After the second conditioning period, samples were taken from the supravalvular, valvular, and subvalvular region of the aortic wall as well as from the valvular cusps.

SEM evaluation. For this procedure, the samples were fixed in a solution of $456 \mathrm{ml}$ aqua bi-distilled (Ampuwa, Fresenius Kabi Deutschland GmbH, Bad Homburg v.d. H., Germany), $0.75 \mathrm{ml} 1 \mathrm{~N}$ hydrochloric acid (Titrisol, Merck KGaA, Darmstadt, Germany), $43.5 \mathrm{ml}$ glutaraldehyde, and 5.65 gm sodium cocodylate trihydrate (Sigma-Aldrich Chemie $\mathrm{GmbH}$, Steinheim, Germany) at $4^{\circ} \mathrm{C}$ for a minimum of 48 hours. Subsequently, they were dehydrated by an ascending ethanol series (30, 50, 70, and 96\%) and 100\% acetone (Merck KGaA, Darmstadt, Germany), followed by critical point drying and gold sputtering $(28 \mathrm{~mA} ; 570 \mathrm{~V})$ of $180 \mathrm{~s}$ at $10^{-5} \mathrm{mbar}$. A "Zeiss Evo LS 10" (Carl Zeiss AG, Oberkochen, Germany) scanning electron microscope was used for microscopy and documentation.

IHC analysis. In IHC evaluation, an indirect staining method was used. After at least 3 days of fixation time in a formalin solution (Roti-Histofix 4\%, Carl Roth $\mathrm{GmbH}$, Karlsruhe, Germany), the samples were embedded in paraffin and sectioned with a thickness of $10 \mu \mathrm{m}$. In a few interim stages, the paraffin was washed out, the cell membrane was permeabilized, and the antigens were unmasked. Samples were incubated for 16 hours at $4^{\circ} \mathrm{C}$ with monoclonal mouse antibodies $(\mathrm{AB})$ against cluster of differentiation (CD)31 (dilution: 1:30; Dianova GmbH, Hamburg, Germany), Human Thymic Fibroblasts Antibody (TE)-7 (0,1 mg/ml; Chemicon-Millipore $\mathrm{GmbH}$, Schwalbach, Germany), smooth muscle cell (SMC)myosin (954 mg/L; DakoCytomation, Hamburg, Germany), -actin (44 mg/L; DakoCytomation), vascular endothelial (VE)-cadherin/CD144 $(0.2 \mathrm{mg} / \mathrm{ml}$; Beckman Coulter $\mathrm{GmbH}$., Krefeld, Germany), connexin-43 (1 mg/ml; Chemicon-Millipore $\mathrm{GmbH})$, fibronectin $(0.6 \mathrm{mg} / \mathrm{ml}$; Sigma-Aldrich $\mathrm{GmbH})$, intercellular adhesion molecule (ICAM; clone: W-CAM-1; dilu-

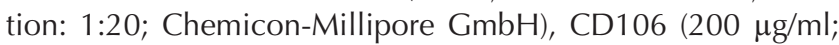

Thermo Fisher Scientific GmbH, Dreieich, Germany), and collagen IV $(5.4 \mathrm{mg} / \mathrm{ml}$; Sigma-Aldrich $\mathrm{GmbH})$. In the following step, the samples were incubated for 30 minutes at RT with the second $A B$ (Dual Link System-HRP, Dianova $\mathrm{GmbH}$ ). This horseradish-peroxidase-linked $A B$ allowed the visualization of the $\mathrm{AB}$ complexes. Furthermore, nuclear counter staining with Mayer's hemalum solution (Merck, Darmstadt, Germany) was performed.

PCR evaluation. Samples, stored in liquid nitrogen, were used for the RNA isolation using RNeasy Plus Mini kit (Qiagen $\mathrm{GmbH}$, Hilden, Germany) according to the manufacturer's protocol. The purity and quantity of the RNA were measured by photometry (BioPhotometer, Eppendorf AG, Hamburg, Germany). Reverse transcription (QuantiTect Reverse Transcription kit, Qiagen $\mathrm{GmbH}$ ) was performed according to Qiagen protocol. For PCR, a Rotor-Gene Q 2plex System (Qiagen $\mathrm{GmbH}$ ) with SYBR Green detection was used. To determine the primer concentration, a dilution series $(1: 5,1: 10,1: 100,1: 1000,1: 10000)$ for standard curve graphing was compiled. During measurement, 35 replication cycles were performed, including, respectively, one negative control using water instead of the primer. Temperatures of $95^{\circ} \mathrm{C}$ (10 seconds) in the denaturation phase and $60^{\circ} \mathrm{C}(30$ seconds) in the replication phase were used. The expressions of interleukin (IL)-1a (QuantiTect Primer Assay IL-1a, Qiagen $\mathrm{GmbH})$, IL-6 (QuantiTect Primer Assay IL-6, Qiagen $\mathrm{GmbH}$ ), IL-8 (QuantiTect Primer Assay IL-8, Qiagen GmbH), monocyte chemotactic protein (MCP)-1 (QuantiTect Primer Assay CCL2, Qiagen $\mathrm{GmbH}$ ), vascular cell adhesion molecule (VCAM; QuantiTect Primer Assay VCAM, Qiagen $\mathrm{GmbH}]$ ), and glyceraldehyde 3-phosphate dehydrogenase (GAPDH; QuantiTect Primer Assay GAPDH, Qiagen $\mathrm{GmbH}$ ) were measured. The obtained Ct-values were normalized to the housekeeping gene GAPDH. The specificity of the PCR products was checked by melting curve analysis (from $60-90^{\circ} \mathrm{C} ;+1^{\circ} \mathrm{C} / 10 \mathrm{sec}$ ) and gel electrophoresis (FlashGel System, Lonza GmbH, Cologne, Germany).

All values are expressed as means \pm standard deviation. Student's t-test was performed for comparison of data; the probability value $p<0.05$ was considered significant. 


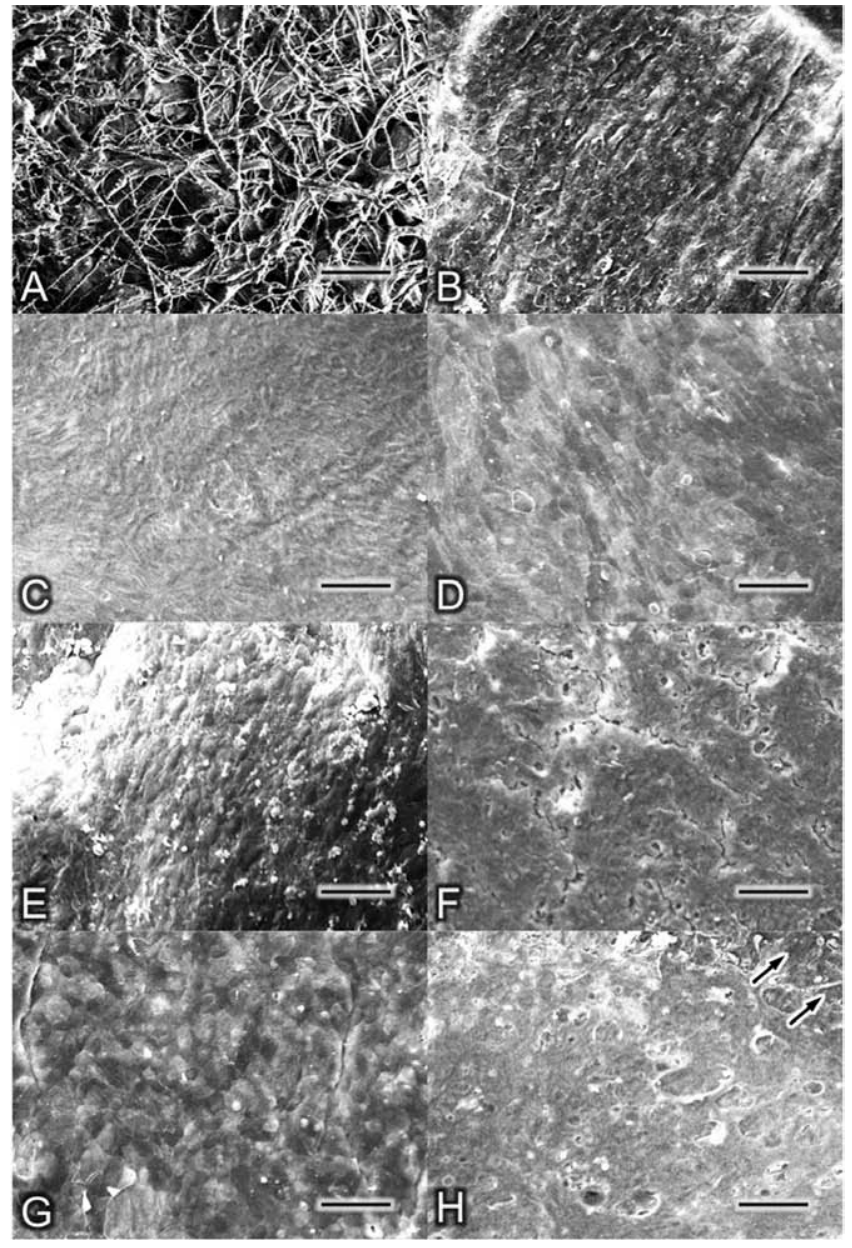

Figure 3. A: Native samples of polyurethane (PU) scaffolds demonstrated randomly orientated fibers with a median diameter of 1.55 $\mu \mathrm{m}$. B: Native samples of the homografts showed an abrasive surface with some cell fragments. C: Complete coverage of the PU fibers after fibroblasts (FB) seeding. The typical fusiform shape of FBs is recognizable. D: Smooth and homogenous surface after FB seeding due to a complete coverage of the scaffold. E: Endothelial cell (EC) seeding of PU scaffolds resulted in a confluent cellular coverage with the characteristic cobblestone pattern. F: EC seeding of the homografts also generated a confluent EC layer. The fissures found on the scaffold are dehydration artifacts. G: A cobblestonelike relief indicates a confluent endothelial lining of PU scaffolds after the second conditioning period. $\mathbf{H}$ : Homografts were also covered with EC after conditioning. A few areas revealed marginal damage (black arrows); samples C, D, E, and F were taken after the resting period ( $24 \mathrm{~h}$ after conditioning). Samples $\mathbf{G}$ and $\mathbf{H}$ were taken directly after the second conditioning period; scale bars: $\mathbf{A}=$ $20 \mu \mathrm{m}, \mathbf{B}-\mathbf{H}=150 \mu \mathrm{m}$.

\section{Results}

\section{Topography of the Scaffolds Surface}

SEM analysis was performed to assess the topography of the cell layer. The recordings showed an uneven, abrasive but homogenous surface in the native samples of both groups (Figure 3, A and B). The structure of the sprayed randomly orientated PU fibers (group A) was clearly visible (Figure 3A).

After FB seeding procedure, a nearly confluent cell layer was visible in both groups. On homograft surfaces at few positions, the cells were not clearly identifiable. Overall, the surface

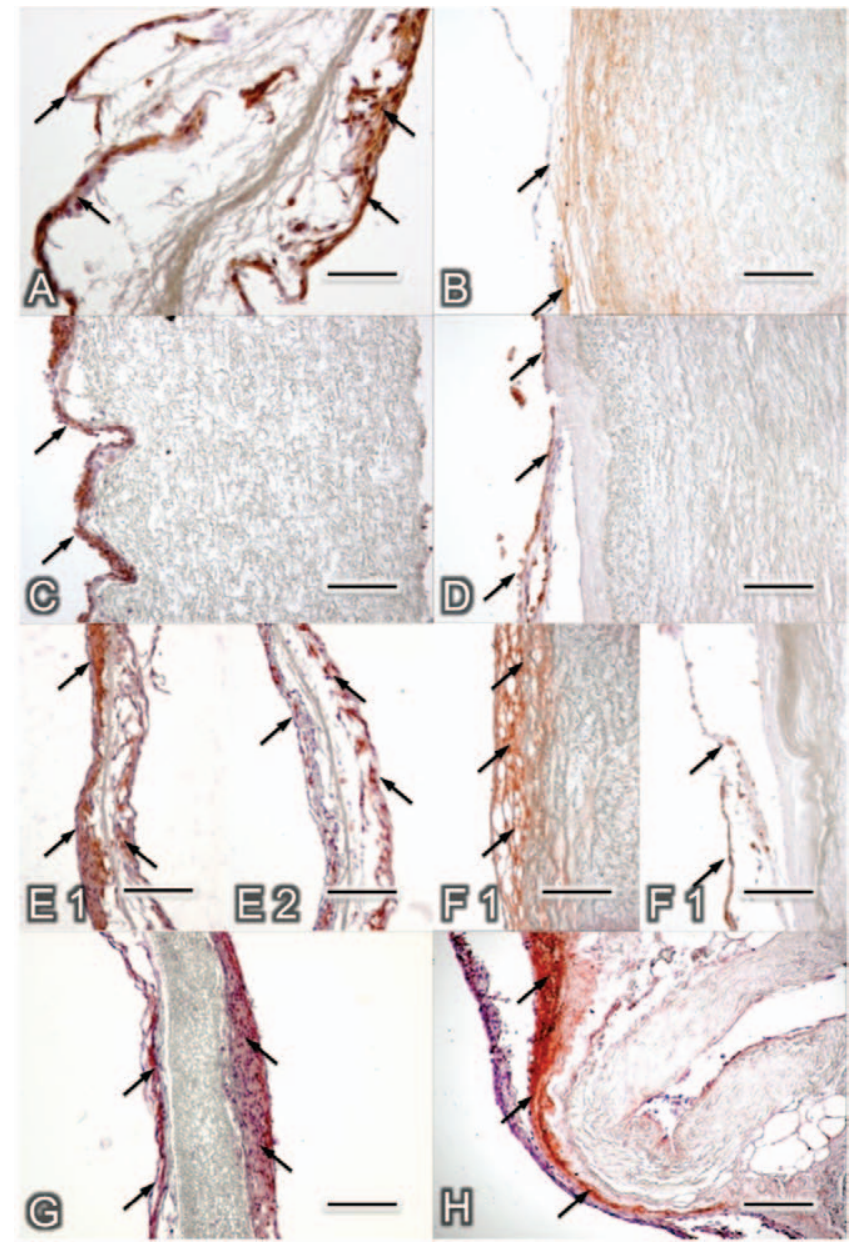

Figure 4. After fibroblasts (FB) seeding, TE-7 staining displayed a compact and confluent FB layer on polyurethane (PU) scaffolds (A; arrows); and a thin cell layer on homografts (B; arrows); staining against CD31 revealed successful endothelial cells (EC) seeding on PU scaffolds (C; arrows) and on homografts (D; arrows). After the final conditioning period, confluent cell layers of FB were detected on PU (E1; arrows) and on homografts (F1; arrows) by staining against TE-7. The presence of EC on the surface of the PU (E2; arrows) and of the homografts (F2; arrows) was demonstrated by CD31 staining. The establishment of a distinct extracellular matrix during the second conditioning period was found by positive staining against Collagen IV on polyurethanes (G; arrows) and homografts (H; arrows). Cell nuclei were stained with hemalaun (purple); scale bars: $300 \mu \mathrm{m}$. CD, cluster of differentiation; TE, human thymic fibroblasts antibody.

appeared smoother and in group A, the PU fibers were completely covered with cells. Partially the fusiform shape of the FB was recognizable (Figure $\mathbf{3}, \mathbf{C}$ and $\mathbf{D}$ ).

The structure of the surface in both groups seemed to be changed after cellularization with EC. The seeded endothelial layer appeared as a cobblestone surface. In group A, a totally confluent cell layer was visible (Figure 3E). In group B, a nearly confluent cell layer was observable; however, several small unseeded regions were noticeable (Figure 3F).

At the end of the second conditioning period, the samples showed a slightly different sight. On several spots the surface of the conditioned homografts seemed lacerated (Figure $\mathbf{3} \mathbf{H}$, arrows). In group A, a few PU fibers were visible. However, nearly the entire surface was covered with a cobblestone-like 
Table 1. Pooled IHC Staining Results

\begin{tabular}{|c|c|c|c|c|c|c|}
\hline & \multicolumn{2}{|c|}{ Cell Culture } & \multirow{2}{*}{$\begin{array}{c}\text { Nativ } \\
\text { Scaffold }\end{array}$} & \multirow{2}{*}{$\begin{array}{l}\text { After FB } \\
\text { Seeding }\end{array}$} & \multirow{2}{*}{$\begin{array}{l}\text { After EC } \\
\text { Seeding }\end{array}$} & \multirow{2}{*}{$\begin{array}{c}\text { After EC } \\
\text { Conditioning }\end{array}$} \\
\hline & $\mathrm{EC}$ & $\mathrm{FB}$ & & & & \\
\hline \multicolumn{7}{|l|}{ Group A } \\
\hline CD 31 & +++ & 0 & ND & 0 & +++ & +++ \\
\hline TE-7 & 0 & +++ & ND & ++ & + & +++ \\
\hline SMC-myosin & ND & ND & ND & 0 & 0 & 0 \\
\hline$\alpha$-actin & ND & ND & ND & + & + & +++ \\
\hline VE-cadherin & ND & ND & ND & + & + & +++ \\
\hline Connexin-43 & ++ & ND & ND & 0 & + & + \\
\hline Fibronectin & ND & +++ & ND & + & + & +++ \\
\hline ICAM & ND & ND & ND & + & ++ & +++ \\
\hline CD 106 & ND & ND & ND & 0 & 0 & + \\
\hline Collagen IV & ND & ++ & ND & + & ++ & +++ \\
\hline \multicolumn{7}{|l|}{ Group B } \\
\hline CD 31 & +++ & 0 & 0 & 0 & ++ & ++ \\
\hline TE-7 & 0 & +++ & $0^{*}$ & $+^{*}$ & $++^{*}$ & $++^{*}$ \\
\hline SMC-myosin & ND & ND & $0 *$ & $0^{\star}$ & $0^{*}$ & $+^{\star}$ \\
\hline$\alpha$-actin & ND & ND & $0^{*}$ & $+^{*}$ & $+^{*}$ & $++^{*}$ \\
\hline VE-cadherin & ND & ND & 0 & 0 & + & ++ \\
\hline Connexin-43 & ++ & ND & 0 & + & + & + \\
\hline Fibronectin & ND & +++ & $0^{\star}$ & $0^{\star}$ & $+^{*}$ & $+++^{*}$ \\
\hline ICAM & ND & ND & $0^{\star}$ & $+^{*}$ & $++^{*}$ & $++^{*}$ \\
\hline CD 106 & ND & ND & 0 & 0 & $0^{\star}$ & $t^{\star}$ \\
\hline Collagen IV & ND & ++ & $0^{*}$ & $0^{*}$ & $+^{*}$ & $+++^{*}$ \\
\hline
\end{tabular}

0 denotes no staining visible; +, light staining; ++, moderate staining; +++, strong staining.

${ }^{*}$ Positive reaction on scaffold material.

CD, cluster of differentiation; EC, endothelial cells; FB, fibroblasts; ICAM, intercellular adhesion molecule; IHC, immunohistochemistry; ND, not done; SMC, smooth muscle cell; TE, human thymic fibroblasts antibody; VE, vascular endothelial.

cell layer (Figure 3G). The cusps were completely coated with a continuous cell layer.

\section{Protein Expression}

The presence of $\mathrm{EC}$ and $\mathrm{FB}$ in the respective cell cultures was displayed by staining against CD31 (EC antibody) and TE-7 (FB antibody). Cell nuclei were stained with hemalaun (A-H purple). The native samples of group B showed no superficial cell layer stainable by hemalaun, but some positive reactions in the internal space of the scaffold wall. Additionally, staining against fibronectin and collagen IV (extracellular matrix [ECM] specific) evoked a strong reaction.

Staining of FB-seeded scaffolds displayed a moderately positive reaction of $T E-7 A B$, pointing to a successful $F B$ seeding procedure (Figure 4, $\mathbf{A}$ and $\mathbf{B}$; arrows). ICAM and $\alpha$-actin ABs also showed a lightly positive reaction (Table $\mathbf{1}$ ). The moderately positive reaction of CD31 AB (Figure 4, C and D; arrows) after the EC seeding procedure suggested successful seeding of EC in both groups. ICAM and collagen IV expression increased, as shown by a stronger staining reaction (Table 1). Strong positive peroxidase reactions in the staining against TE-7 and CD31 of both groups after the second conditioning procedure confirm the unchanged presence and integrity of the FB and EC layers, respectively (Figure 4, E1, E2, F1, F2; arrows). An enhancement of ECM and cellular adhesion after the EC conditioning period was detected by a strong, intensified positive reaction of $\alpha$-actin, VE-cadherin, fibronectin, ICAM, and collagen IV (Figure 4, $\mathbf{G}$ and $\mathbf{H}$, arrows; Table $\mathbf{1}$ ). A higher expression of ECM was observed on the scaffold's inner surface.

\section{Gene Expression}

Figure 5 demonstrates the mean values of gene expression before and after the conditioning period of FB-seeded as well as FB- and EC-seeded PU valves and homografts, respectively. Gene expression was normalized to the expression of the housekeeping gene GAPDH. The analysis of different segments of the heart valves (aortic wall and cusps) in both groups showed equivalent gene expressions for all cytokines and chemokines.

IL-1a and VCAM presented a negligible expression in both groups during the whole experiment. Negligible pro-inflammatory gene expression change of IL-6 $(-1.12 \%)$ was detected while the seeded FB layer in Group A (Figure 5A) was conditioned, whereas the level of IL-8 gene expression decreased $(-59.48 \%)$ and an increase of MCP-1 $(+138.78 \%, p<0.05)$ was detected during the conditioning of $\mathrm{FB}$ in group $\mathrm{A}$. An increase in the expression of most genes was observed (IL-6: +122.61\%; IL-8: $+454.38 \%$; MCP-1: +45.39\%) in group B (Figure 5B).

In both groups, the endothelialization caused a decrease in inflammatory cell response (group A, Figure 5A: IL-6: $-78.82 \%$; MCP-1: $-68.71 \%$; group B, Figure 5B: IL-6: $-97.42 \%$; IL-8: $-67.01 \%$; MCP-1: $-89.44 \%, p<0.05)$. For IL-8 in group A only, an increase of $+559.7 \%(p<0.05)$ was observed. Nonetheless, IL-8 expression after endothelialization is slightly lower than that in group B.

During the second conditioning step of the scaffold colonized with FB and EC, a slight decrease in IL-8 (group A, Figure 5A: $-66.23 \%$; group B, Figure 5B: $-13.98 \%$ ) was observed. IL-6- and MCP-1 expression was approximately on the same level in this period. 

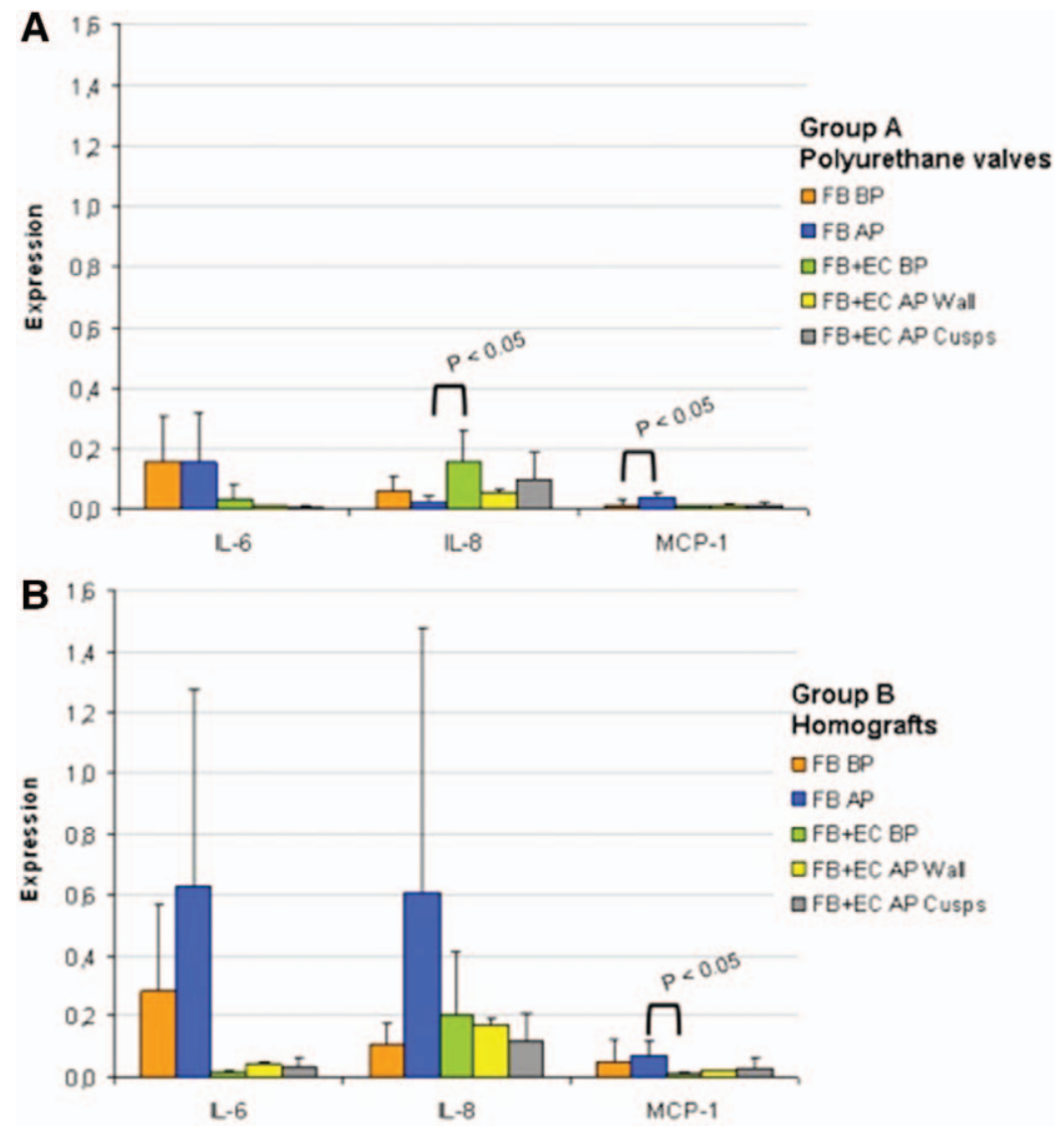

Figure 5. Cyto- and chemokine expressions of fibroblast and fibroblast-endothelial cell seeded scaffolds before (BC) and after conditioning (AC) A: Gene expression of interleukin (IL)-6, IL-8, and monocyte chemotactic protein (MCP)-1 in cells seeded onto polyurethane valves: fibroblasts (FB) conditioning induced a decrease in IL-8 and an increase in MCP-1 expression. IL-6 expression remained at a constant level. The endothelialization step caused decrease in IL-6 and MCP-1 expression. Measured IL-8 increased in this step, which regresses in the following conditioning step. For IL-6 and MCP-1 no significant change was observed during endothelial cell (EC) conditioning. B: Gene expression of IL-6, IL-8, and MCP-1 in cells seeded on homografts: conditioning of FB causes an increase of the gene expression of IL-6, IL-8, and $\mathrm{MCP}-1$, which is regressive after EC seeding. EC conditioning does not cause a significant change in gene expression. No significant difference was found between the gene expression of cells in aortic walls and cusps in either group; samples were taken directly BC and AC periods; values are normalized to glyceraldehyde 3-phosphate dehydrogenase (GAPDH).

\section{Discussion}

The mean age of patients requiring cardiac valve replacement increases every year. ${ }^{12}$ Therefore, the most beneficial form of therapy seems to be the extraction and the use of adult cells with good cultivation characteristics for the manufacturing of a tissue engineered heart valve. It has already been described that cells of aortic valvular origin appear as one of the most suitable cell types for aortic valve tissue engineering; however, there is no reasonable mode of autologous application. ${ }^{13}$ On the other hand, cell source comparisons, also performed in our department, ${ }^{14}$ have shown excellent results for cells isolated from saphenous vein segments. ${ }^{15,16}$ Corresponding to these results, a specific isolation of $E C$ and $F B$ from saphenous vein segments was possible, a good replication rate in cell culture enabled a fast usage, and good conditioning attributes were observed. Considering these arguments, this cell source seems to be a good consensus concerning a practicable harvesting and the creation of a durable and viable tissue engineered aortic valve for an autologous application.

In the choice of the scaffold, several reasons militated for taking a nondegradable material, such as $\mathrm{PU}$, for a tissue engineered aortic heart valve. Polyurethane is known as one of the most bio- and hemocompatible materials used in the development of medical devices. ${ }^{17}$ However, aging of PU has been found to be a possible drawback of this material in clinical studies. Nevertheless, its degradation rate is significantly lower than that of most degradable materials used for tissue engineering applications (e.g., polyglycolic acid and polylactic-coglycolic acid). ${ }^{18,19}$ Another reason against degradable scaffolds is the high pressure stress in aortic position, meaning that proper function and a high life expectancy cannot be guaranteed. ${ }^{20,21}$ Under these conditions, just decellularized homografts showed a promising in vivo short- and mid-term performance. ${ }^{22-24}$ Baraki et al. ${ }^{23}$ showed in their comparison between decellularized homografts and a native control group that the decellualrized valves had even a better outcome concerning morphology and function after 9 months in systemic circulation. A drawback of this kind of scaffold is, however, the limited availability of homografts. ${ }^{25}$ Up to now, synthetic degradable materials proved their qualification only in pulmonary arterial position. ${ }^{6}$ The uncontrollable absorbability and the possible inflammatory reaction during the resorption time are additional arguments against biodegradable materials., ${ }^{4,26}$ 
The untreated cryoconserved/thawed homografts, which are established prostheses in modern heart surgery, were used as a control group in our study. In this way, it was possible to compare the behavior of seeded cells on native tissue and synthetic scaffold. The absence of endothelial and interstitial cells on native homografts surface, shown by negative CD31- and HEstaining results, could be explained by the cryopreservation process. Confirming these results, Lupinetti et al. ${ }^{27}$ showed that cryopreservation of homografts can result in a severe loss of EC coverage.

In all experiments, both scaffold materials showed an adequate cell-seeding efficiency and presented a nearly completely confluent FB cell layer on the surface. The already described preseeding with FB resulted in a good subsurface for a confluent EC layer with good cell adherence. ${ }^{12}$ The achieved intact endothelial surface plays a decisive role for the avoidance of the anticoagulation therapy in a following in vivo use. ${ }^{2}$ Additionally, the endothelialization caused a desirable decrease in IL-6 and MCP-1 gene expression in both groups. Due to the known importance of these cytokines and IL-8 on inflammatory reaction, a downregulation in a targetcell-free surrounding is crucial. ${ }^{28,29} \mathrm{~A}$ low inflammatory cell response plays in vivo a decisive role in the healing process after a heart valve implantation and the long-term functionality of a bio-prosthetic valve. ${ }^{30}$ However, IL-8 is also known as a pro-proliferative, a pro-angiogenic, and anti-apoptotic cytokine. ${ }^{31,32}$ This might explain the persistent expression after endothelialization and during the second conditioning period.

An essential component of each tissue is a specific ECM. ${ }^{33}$ To provoke the establishment of an ECM by the seeded cells of a tissue engineering construct, an appropriate stimulus is necessary. In cardiovascular tissue engineering, Jockenhoevel et al. ${ }^{34}$ and other research groups showed that flow-depending mechanical stress induces ECM formation. ${ }^{35}$ In line with these results, the establishment of an ECM and the habituation of the cells were observed during the 5-day conditioning periods, demonstrated by positive staining against collagen IV and fibronectin. An increased ECM growth on scaffolds' inner/flow surface proved the flow dependence. The major construction of the ECM was observed during EC conditioning and due to the increased inflammatory influence, the first conditioning period did not appear to be beneficial. Additionally, the desired effect of downregulation of chemotactic factors, such as IL-8 and MCP- $1,{ }^{29}$ was mainly observed after endothelialization. So, longer resting periods and longer EC conditioning for a further decrease in inflammatory cell reaction and less possible arteriosclerotic effects should be investigated. ${ }^{36}$

The PU scaffold showed a good cell-seeding efficiency and provoked no higher, or even a lower, inflammatory cell reaction during the whole experiment. The endothelialization results were similar in the control group (group B). In summary, the PU scaffolds proved their good biocompatibility. Our conditioning bioreactor allowed the cells to adapt to shear stress by establishing a strong ECM. At this point, these results cannot yet be transferred to the in vivo environment; however, the results have suggested that the polymer-based scaffold is a good candidate for this step. Thus this new tissue engineered heart valve may offer a new option for aortic valve replacement surgery.

\section{Acknowledgment}

The authors thank the ITV-Denkendorf and especially Dr. -Ing. Martin Dauner for his support in manufacturing the synthetic scaffolds. Additionally, we thank Ulrike Haas and Antje Uhlig for their help in the evaluation of the experiments.

\section{References}

1. Yacoub $\mathrm{MH}$, Takkenberg J): Will heart valve tissue engineering change the world? Nat Clin Pract Cardiovasc Med 2: 60-61, 2005.

2. De Campos NL, de Andrade RR, Silva MA: Oral anticoagulation in carriers of mechanical heart valve prostheses: experience of ten years. Rev Bras Cir Cardiovasc 25: 457-465, 2010.

3. Hoffmann G, Lutter G, Cremer J: Durability of bioprosthetic cardiac valves. Dtsch Arztebl Int 105: 143-148, 2008.

4. Mendelson K, Schoen FJ: Heart valve tissue engineering: concepts, approaches, progress, and challenges. Ann Biomed Eng 34: 1799-1819, 2006.

5. Langer R, Vacanti JP: Tissue engineering. Science 260: 920-926, 1993.

6. Sodian R, Hoerstrup SP, Sperling JS, et al: Early in vivo experience with tissue-engineered trileaflet heart valves. Circulation 102(19 suppl 3): III22-III29, 2000.

7. Lichtenberg A, Cebotari S, Tudorache I, Hilfiker A, Haverich A: Biological scaffolds for heart valve tissue engineering. Methods Mol Med 140: 309-317, 2007.

8. Gulbins H, Dauner M, Petzold R, et al: Development of an artificial vessel lined with human vascular cells. J Thorac Cardiovasc Surg 128: 372-377, 2004

9. Gulbins H, Pritisanac A, Uhlig A, et al: Seeding of human endothelial cells on valve containing aortic mini-roots: development of a seeding device and procedure. Ann Thorac Surg 79: 21192126, 2005.

10. Gulbins H, Goldemund A, Anderson I, et al: Preseeding with autologous fibroblasts improves endothelialization of glutaraldehyde-fixed porcine aortic valves. I Thorac Cardiovasc Surg 125: 592-601, 2003.

11. Koenig F, Hollweck T, Pfeifer S: A pulsatile bioreactor for conditioning of tissue-engineered cardiovascular constructs under endoscopic visualization. J. Funct. Biomater. 3, 480-496, 2012.

12. Yacoub MH, Cohn LH: Novel approaches to cardiac valve repair: From structure to function: Part I. Circulation 109: 942-950, 2004.

13. Butcher JT, Penrod AM, García AJ, Nerem RM: Unique morphology and focal adhesion development of valvular endothelial cells in static and fluid flow environments. Arterioscler Thromb Vasc Biol 24: 1429-1434, 2004.

14. Schaefermeier PK, Cabeza N, Besser JC, et al: Potential cell sources for tissue engineering of heart valves in comparison with human pulmonary valve cells. ASAIO J 55: 86-92, 2009.

15. Schnell AM, Hoerstrup SP, Zund G, et al: Optimal cell source for cardiovascular tissue engineering: venous vs. aortic human myofibroblasts. Thorac Cardiovasc Surg 49: 221-225, 2001.

16. Schmidt D, Hoerstrup SP: Tissue engineered heart valves based on human cells. Swiss Med Wkly 136: 618-623, 2006.

17. Zdrahala RJ, Zdrahala IJ: Biomedical applications of polyurethanes: A review of past promises, present realities, and a vibrant future. J Biomater App/ 14: 67-90, 1999.

18. Szycher M: Biostability of polyurethane elastomers: A critical review. J Biomater App/ 3: 297-402, 1988.

19. Kim MS, Kim JH, Min BH: Polymeric scaffolds for regenerative medicine. Polymer Reviews 51: 23-52, 2011.

20. Weston MW, LaBorde DV, Yoganathan AP: Estimation of the shear stress on the surface of an aortic valve leaflet. Ann Biomed Eng 27: 572-579, 1999

21. Balachandran K, Sucosky P, Yoganathan AP: Hemodynamics and mechanobiology of aortic valve inflammation and calcification. Int J Inflam 2011: 263870, 2011.

22. da Costa FD, Costa AC, Prestes R, et al: The early and midterm function of decellularized aortic valve allografts. Ann Thorac Surg 90: 1854-1860, 2010. 
23. Baraki H, Tudorache I, Braun M, et al: Orthotopic replacement of the aortic valve with decellularized allograft in a sheep model. Biomaterials 30: 6240-6246, 2009.

24. Akhyari $\mathrm{P}$, Kamiya $\mathrm{H}$, Gwanmesia $\mathrm{P}$, et al: In vivo functional performance and structural maturation of decellularised allogenic aortic valves in the subcoronary position. Eur / Cardiothorac Surg 38: 539-546, 2010.

25. Delmo Walter EM, de By TMMH, Meyer R, Hetzer R: The future of heart valve banking and of homografts: perspective from the Deutsches Herzzentrum Berlin. HSR Proceedings in Intensive Care and Cardiovascular Anesthesia 4: 97-108, 2012.

26. Filová E, Straka F, Mirejovský T, Masín J, Bacáková L: Tissueengineered heart valves. Physiol Res 58 suppl 2: S141-S158, 2009.

27. Lupinetti FM, Tsai TT, Kneebone JM, Bove EL: Effect of cryopreservation on the presence of endothelial cells on human valve allografts. J Thorac Cardiovasc Surg 106: 912-917, 1993.

28. Van Snick J: Interleukin-6: an overview. Annu Rev Immunol 8: 253-278, 1990.

29. Mukaida N, Harada A, Matsushima K: Interleukin-8 (IL-8) and monocyte chemotactic and activating factor (MCAF/MCP-1), chemokines essentially involved in inflammatory and immune reactions. Cytokine Growth Factor Rev 9: 9-23, 1998.
30. Simionescu A, Schulte JB, Fercana G, Simionescu DT: Inflammation in cardiovascular tissue engineering: the challenge to a promise: a minireview. Int J Inflam 2011: 958247, 2011.

31. Li A, Dubey S, Varney ML, Dave BJ, Singh RK: IL-8 directly enhanced endothelial cell survival, proliferation, and matrix metalloproteinases production and regulated angiogenesis. J Immunol 170: 3369-3376, 2003.

32. Heidemann J, Ogawa $H$, Dwinell MB, et al: Angiogenic effects of interleukin 8 (CXCL8) in human intestinal microvascular endothelial cells are mediated by CXCR2. J Biol Chem 278: 85088515, 2003.

33. Bosman FT, Stamenkovic I: Functional structure and composition of the extracellular matrix. J Pathol 200: 423-428, 2003.

34. Jockenhoevel S, Zund G, Hoerstrup SP, Schnell A, Turina M: Cardiovascular tissue engineering: a new laminar flow chamber for in vitro improvement of mechanical tissue properties. ASAIO J 48: 8-11, 2002.

35. Sierad LN, Simionescu A, Albers C, et al: Design and testing of a pulsatile conditioning system for dynamic endothelialization of polyphenol-stabilized tissue engineered heart valves. Cardiovasc Eng Technol 1: 138-153, 2010.

36. Szmitko PE, Wang CH, Weisel RD, de Almeida JR, Anderson TJ, Verma S: New markers of inflammation and endothelial cell activation. Circulation 108: 1917-1923, 2002. 